\title{
LOCALIZING THE GLOBAL VILLAGE: INCORPORATING HYPERLOCAL SOUTH ASIAN INSIGHTS INTO GLOBAL DIGITAL MARKETING PRACTICES
}

\author{
Aradhya Munjal \\ modern school barakhamba road, New Delhi \\ DOI: 10.46609/IJSSER.2020.v05i12.016 URL: https://doi.org/10.46609/IJSSER.2020.v05i12.016
}

\begin{abstract}
With the increased connectivity and internet usage in South Asia, countries in the region are becoming more attune to their needs as consumers. The digital marketing industry must become aware that South Asian consumers expect engagement to their particular cultures, and messages that resonate with their communities. However, the existing digital marketing standards are based on ideas of Eurocentrism and Western universality, with only a minimal element of tailoring content to local cultures. While tailoring content is important, structural changes in the industry and digital marketing standard operating procedures are required to incorporate South Asian perspectives and adopt a more inclusive approach to marketing as a whole. This paper will critique the existing scenario in the digital marketing industry, and propose measures that could be adopted to implement a more inclusive framework that also produces goodwill and better reputations for businesses adopting such marketing strategies. This paper will further emphasize the need for structural changes within the industry and what Western marketers must be aware of with respect to the South Asian economy and demographic.
\end{abstract}

Keywords: Localizing, Digital Marketing, Business, Village, Consumers.

\section{Introduction}

With a boom in social media usage and e-commerce entities, businesses have been required to adapt rapidly and incorporate digital marketing techniques, to reach consumers and effectively compete on a global and interconnected landscape where most all business has taken a form online. With the increase of targeted advertising, it has also been crucial for businesses to use of digital channels to promote or market products and services to targeted consumers and businesses (Monnappa, 2020). Data available from surveys conducted in the USA in 2014, showed that $99 \%$ of digital marketers use Facebook to market, 97\% use Twitter, 69\% use Pinterest and $59 \%$ use Instagram. $70 \%$ of B2C marketers have acquired customers through 


\section{International Journal of Social Science and Economic Research}

ISSN: $2455-8834$

Volume:05, Issue:12 "December 2020"

Facebook. 67\% of Twitter users are far more likely to buy from brands that they follow on Twitter (Monnappa, 2020). Therefore, the industry is ever evolving and increasingly global.

However, with the increasingly global nature of the digital marketing space comes a concern of a lack of democratization. The current scenario pertaining to digital marketing continues to be largely Eurocentric and Western oriented in marketing techniques and methods, as well as the messaging that businesses must employ to sell their products. Therefore, there have been calls and critiques which emphasize on the need for inclusive digital marketing, which are practices that incorporate representation from different communities, and are inclusive of consumers regardless of race, ethnicity, and sexual orientation, among several other categories. This must necessarily include the incorporation of South Asian perspectives into digital marketing practices, given the rapid growth of social media and internet usage in South Asia as well as among South Asian populations within Western countries. It is estimated that companies across APAC will more than double spending by 2018, up from $\$ 46.59 \mathrm{bn}$ in 2014 to $\$ 96.40 \mathrm{bn}$ (Found, 2020). As countries like India and China grow into true economic powerhouses and the avenues to leverage digital marketing increase, the opportunity for expansion is huge (Found, 2020).

This paper will shed light upon the Eurocentric and Western oriented standards that currently exist in the digital marketing industry, and critique the current modes of engagement used. The paper will emphasize the importance of inclusive digital marketing in other spheres, and how this may be incorporated to further include South Asian perspectives and contexts. The paper will then discuss the potential implications for digital marketing practices in the future, and the way forward.

\section{Background}

A study conducted by Oxford Economics and Dentsu Aegis Network found that consumers from Asia-Pacific countries are continuing to increase their use of digital products and services, sometimes more quickly than their peers in other parts of the world (Sentance, 2019). Further, analysis from research firm Media Partners Asia has revealed that the online video market in Asia Pacific is set to double in size over the next five years, driven by increased mobile broadband connectivity (Sentence, 2019). However, the standards and metrics of the industry continue to be largely Eurocentric and ignorant of multicultural diversity and varying identities. Further, there is a prevailing sentiment in the industry that suggests Asia-based marketers, including those in India and Australia, lack a level of 'maturity' or 'savviness' on digital compared to the markets of the US or Europe (Hochuli, 2018). Standards in the industry are Eurocentric due to the lack of representation in the decision making processes. 


\section{International Journal of Social Science and Economic Research}

ISSN: $2455-8834$

Volume:05, Issue:12 "December 2020"

Asia-based marketers have to deal with the cultural and political nuances of over 48 countries, instead of one market with one culture, like the US. They regularly have minimal say on the content creation or distribution process for their region because all strategic marketing decisions sit at 'head office' - normally based in the US or Europe (Hochuli, 2018). Asia-based marketers are also under resourced and are often forced to wear many hats just to deliver the basic tasks; whilst their Western counterparts usually have a much better resourced team - which includes the luxury of specialists (Hochuli, 2018). The reason why regional agencies and brands are often underrepresented in many global marketing awards is this friction (Hochuli, 2018).

Due to disparities in budgeting, most Asian content is also curated from the West. It is easier and cheaper to scale and re-purpose Western-centric marketing material to Asia, than it is to have a separate Asia-based marketing team create new content for each region. But this push for scale comes at a cost to performance (Hochuli, 2018). Western-centric content is often irrelevant for the Asian market, which results in lacklustre engagement and regional performance (Hochuli, 2018)

Therefore, modes of audience engagement, search engine optimization and standards of beauty, quality and reference are usually all borrowed from Western culture, and adopted within digital marketing techniques. For example, the cosmetic industry continues to have a lack of diversity in the manner in which cosmetics are both manufactured and advertised, to incorporate the representation of South Asian women and other women of colour. However, there is potential for such practices to change. Brands like Rihanna's Fenty Beauty, which places "beauty for all” at the core of its marketing messaging, understand what happens when you help people bring out the best in themselves (Xavier, 2020). Within a year, Fenty became the biggest beauty brand launch in YouTube history. South Asian women and other women of colour responded to the representation in the branding message (Xavier, 2020). Therefore, in order to incorporate South Asian perspectives into digital marketing practices, it is crucial to first accept a broader notion of the need for inclusivity, and for rejecting templates that only cater to a particular Western audience of consumers. This has implications for businesses to also become far more successful, taking from the example of Fenty.

\section{Discussion}

As emphasized in the previous section of this paper, the need to incorporate South Asian perspectives must necessarily stem from a notion of inclusivity and diversity. Stock photo agency Shutterstock has conducted research about how society, culture and people are represented in visuals for the past three years (Aikens, n.d). In October 2018 they partnered with Censuswide to question 2,500 marketers across the globe about how they select and use photos in their content (Aikens, n.d). In this survey, it was found that 88 percent of Generation X and 90 


\section{International Journal of Social Science and Economic Research}

ISSN: 2455-8834

Volume:05, Issue:12 "December 2020"

percent of Millennials believe "a diverse representation in their campaigns" help a brand's reputation (Aikens, n.d). Further, incorporating South Asian culture and insights must include taking into account a vastly different sense of relatability and community (Chang, 2010). In Asia, as compared to the west, there is still a greater sense of community that can influence consumer behavior. Further, many markets in Asia are turbulent and evolving. Therefore, it will not be feasible to incorporate standard operational procedures that are often adopted in the Western world (Chang, 2010). A standard template based methodology and units of analysis will necessarily have to be made more flexible to better fit the market conditions of Asia and reach communicate with Asian consumers (Chang, 2010).

In addition, catering to the local market through local channels is most crucial to develop a strategy of inclusivity. For example, in China, the market for paid advertising on Google is saturated because of the dominating influence of Baidu as a search engine. Therefore, search engine optimization must take into account the structural factors in each country in order to make the effort to reach those customers (Smart Insights, 2017). Although the examples pertaining specifically to South Asian perspectives are very few outside of the South Asian economy itself, there are other examples which demonstrate that inclusivity in digital marketing is possible and when approached with sensitivity to culture and diversity in background. For example, Proctor and Gamble in 2018 put out a commercial to raise awareness about the impact of bias and to expose the unthinkable closed-door conversations that African American mothers need to have with their children to keep them safe and strong in the face of racism (Bump, n.d). Google's ad campaign for their Pixel smartphone aims to represent and identify with people dealing with mental illness while informing viewers that friends, family, or loved ones might seem happy or put together on the outside while still struggling behind closed doors (Bump, n.d). While this content might educate viewers about mental health, it also informs those with these struggles that Google identifies with them and that there are resources that can help (n.d).

In both these examples, it is clear that methods of integrating such insights in an inclusive fashion do not have to compromise on profits of the company or brand reach, and in fact allows the company to gain a large return on their investment due to the goodwill generated and the reputation amongst consumers as an aware, diverse company. Incorporating messaging and producing specific campaigns that understand the issues of the population can go a long way for companies, in showing that they are conscious of the needs of different demographics of consumers. To reach the South Asian market, researchers suggest that it will not be enough to adopt a message of being 'global', in order to compete with homegrown firms. What will be crucial is to truly adapt to local sensibilities and disregard the existing methodology that treats Western marketing methods as universal (Chang, 2010; Whitler, 2019). It will not only be adequate to customize marketing content and channel selection, but to delve into the local market 


\section{International Journal of Social Science and Economic Research}

ISSN: $2455-8834$

Volume:05, Issue:12 "December 2020"

in-depth, adopt a marketing mindset that fundamentally moves away from Eurocentric universality, and develop new competencies (Whitler, 2019).

\section{Conclusion}

The future of digital marketing must necessarily be one that is inclusive, not only with respect to South Asian contexts and perspectives, but from a holistic stand point. The industry must consider all facets and layers of a person's identity such as skin tone, gender identity, age, sexual orientation, body type, ethnicity, culture, language, religion/spirituality, physical/mental ability, socio-economic status and mindset (Xavier, 2020). It should also account for intersectionality, which means recognising that a single person may represent many identities or dimensions and acknowledging the nuances inherent in every individual's personality and preferences (Xavier, 2020). Therefore, it is crucial that inclusive digital marketing not only be approached from a stand point of efficiency or streamlining, but from a true attempt to reach a more diverse audience.

To this end, there are a few methods that are indicative of the direction in which digital marketing practices must head. Digital marketers must be aware of important holidays celebrated by the most populous Asian American groups such as Chinese New Year, Diwali, Holi, Eid, Tet and Christmas (Snipp, 2016). It is worth mentioning that since many Asian holidays follow a lunar calendar, the holidays are not celebrated on the same day each year. Marketers must also be aware of the differences in South Asian identities, such as Chinese, Korean, South East Asian, Filipino, etc (Snipp, 2016). Marketers must address their individual cultural nuances by segmenting their data and customizing content, imagery and creative for each group. One way to do this would be through highly-customized, dual-language messaging (Snipp, 2016). Marketers can also be inclusive by providing unique and relevant content. An example of this approach is the content provided by Buzzfeed which is relatable and provides funny perspectives that cater to various sections of the population based on their upbringing. Digital marketers can identify such platforms and collaborate with them.

A broad stroke 'global' marketing strategy is often governed by objectives such as scale and cost rather than regionalisation and creativity, which requires a fundamental change. Further regional divisions of digital marketing companies that are based in the USA or Europe must be encouraged to develop region specific content, have increased autonomy, and increased budgets. Such structural changes in the industry will allow for inclusivity and South Asian perspectives to be incorporated within standard operating procedures and marketing practices (Hochuli, 2018). Western brands must put their faith into Asian marketers and recognize that local Asian brands with properly resourced local Asian teams are actually creating some very innovative content 
International Journal of Social Science and Economic Research

ISSN: 2455-8834

Volume:05, Issue:12 "December 2020"

(Hochuli, 2018). Such a perspective will only better the models of the digital marketing company and improve the reach of businesses and their goodwill.

\section{References}

Aikens, C, (n.d), 'What Does Diversity and Inclusion Look Like in Digital Marketing?', Volume Nine, https://www.v9digital.com/insights/what-does-diversity-and-inclusion-look-like-in-digitalmarketing/

Bump, P, (n.d), '7 Brands That Got Inclusive Marketing Right', Hubspot Blog, https://blog.hubspot.com/marketing/inclusive-marketing-campaigns

Chang, DR, (2010), 'In Asia, Marketing 101 Doesn’t Work', Harvard Business Review, https://hbr.org/2010/02/in-asia-marketing-101-doesnt-work.html

Found, S, (13 July 2020), 'How is Digital Marketing Expanding in Asia?', Innovation Enterprise, https://channels.theinnovationenterprise.com/articles/how-is-digital-marketing-expanding-in$\underline{\text { asia }}$

Hochuli, D, (2018), 'No, Asia is not behind the West in digital marketing', Mumbrella Asia

Monnappa, A, (2020), 'The History and Evolution of Digital Marketing', SimpliLearn, https://www.simplilearn.com/history-and-evolution-of-digital-marketing-article

Sentance, R, (2019), 'The best Asia-Pacific digital marketing stats from April 2019', Econconsultancy, https://econsultancy.com/best-apac-digital-marketing-stats-april-2019/

Smart Insights, (2017), 'How to develop an international digital marketing strategy', https://www.smartinsights.com/online-brand-strategy/international-marketing/developinternational-digital-marketing-strategy/

Snipp, (n.d), 'Diverse and Digital White Paper', https://www.snipp.com/wpcontent/uploads/2016/11/Snipp-Resources-Whitepaper-Marketing-to-Asian-Americans.pdf

Whitler, KA, (2019), 'What Western Marketers Can Learn from China', Harvard Business Review, https://hbr.org/2019/05/what-western-marketers-can-learn-from-china

Xavier, R, (2020), 'Let's talk about inclusive marketing', Accenture Blog, https://www.accenture.com/us-en/blogs/interactive-insights-blog/lets-talk-inclusive- 
International Journal of Social Science and Economic Research

ISSN: 2455-8834

Volume:05, Issue:12 "December 2020"

marketing\#: :text=Inclusive $\% 20$ marketing $\% 20$ refers $\% 20$ to $\% 20$ the,experience $\% 20$ and $\% 20$ conn ect $\% 20$ with\%20brands. 